180 Lalhyrus angustifolius. Bläuung des Guajalharzes.

herum am meisten abgelagert ist. Auch die im Keller schon ausgelaufenen Schösslinge bläuen die Tinctur slark. Grössere Mengen der Guajaklinetur können durch Kartoffelschalen gebläuet werden, worauf sich diese ebenso verhält, wie die mit Braunstein etc. behandelte Tinctur. (Poggend. Annal - Pharm. Centrbl. 1849. No.11.) B.

\title{
Bestandtheile der Samen von Lathyrus angustifolius.
} angestellt.

H. Reinsch hat einige Versuche über diese Samen

Er fand, dass sie geröstel einen den Caffeebohnen ähnlichen Geruch entwickelten, aber einen sehr bittern Aufguss gaben. $\mathrm{Er}$ behandelte gestossenen Samen mit 80procentigem Alkohol, die Tinctur enthielt den Bitterstoff und etwas wachsartiges Oel, das er mittelst Aethers aus dem zur Syrupsdicke verdampften Auszuge schied. Der unreine Bitterstoff ward mit 94 procentigem ätherhaltigem Weingeist behandelt, wobei Leimstoff zurückblieb. Die lösung war nicht krystallisirbar und hinterliess beim Trockenwerden eine gelbliche, klare, doch noch weiche Masse von intensiv bitterm Geschmack.

Im Ruickstande des Samens wurden Pflanzeneiweiss, Pflanzenleim, Gummi und Salze gefunden; der Pressrüchstand gab nach dem Auszuge mil Wasser Stärkmebl und Pflanzenfaser. (Jahrb. fiir pralkt. Pharm. Bd. 17. p. 38.) $B$.

\section{Bläuung des Guajaliharzes.}

Ueber das Blauwerden der Guajaktinctur durch Ozon, Luft, Chlor, Brom, Superoxyde macht Schö n be in Versuche bekannt, welche zeigen, dass die nach einiger Zeit von selbst ihre ursprüngliche Farbe wieder annehmende Tinctur sich zwar von neuem wieder durch dieselben Mittel bläuet, dass es aber mit dieser wiederholt eintretenden Erscheinung seine Grenzen hat; nach mehrfacher Bläuung und Entbläuung wird das Harz in Lösung, wie es scheint, chemisch verändert, worauf es nicht mehr durch dasselbe Mittel, mitunter aber noch durch ein anderes blau wird. Das aus gebläuter Tinctur durch Wasser in festem Zustande blau niedergeschlagene Harz scheint sich an der Luft nicht weiter zu verändern.

Zu den das Harz bläuenden Milleln gehören noch ferner: Eisenchlorid, Kupferchlorid, Quecksilberchlorid, Silber- 
oxyd, chromsaures und übermangansaures Kali, alles solchle Substanzi:n, welche Jodkaliumkleister ebenfalls bliuen. (Poggetd Annal - Pharm. Centrbl. 1819. No. 10.) B.

\section{lïn narkotisches Extract aus Glaucium.}

X. Landerer berichtel, dass aus Glaucium luteum und Gl. rubrum, welche zur Familie der Papareraceale gobörendın Pflanzen um Athen ziemlich häulig sind, von einem Kiriutersammler vermittelst in die Schoten gemachter Einsilunitte und durch Auskochen ein Extract beresitet werdo (Ji:xtr. Glaucii), welches er in Athen als Opium angetorik" habe. Das Extr. Glaucii besass einen uichit unbedkutenden narkotischen Geruch und sehr bittern opiumähnliclien Geschmack. es war einer sehr schlechten Sorte Smyrnikcr Opium sebr ähnlich. Landerer bält diese Mittheilung in so fern wichtig, als er von glaubwiirdigen P'erson'n. unter anderm auch von einem gebildeten Pliarmaceulı:t aus Smyrna hörte, dass die Opiumberciter daselbst di ise Pflanzen. besonders das rothe, das Gil. rub. thoenir, in Ilabitus bekanntlich dem Papaver sehr ialunlich, $n$ it zur Opiumbereitung gebrauchen sollen, und heinahe till's auf den Bazars von Smyrna sich findente Opium. Ilis an die Leute ohne alle Aufsicht verhauft wirl, nichts al; cin Extract aus genannter Pflanze sci. Aus die:sem fillschlich genannten Opium soll auch aller Theriac;, den miall ebenfalls auf den Bazars für wenige Paras belommin kann, so wie das mit Fett gekochte Chaschisch bereitcl werden. (Buchn. Rep. Bd.49. Hft.3.) Oterbecl.

\section{Untersuchung einiger Stoffe aus der Familie der Menispermeen. \\ 1) Columbin.}

Dic unter dem Namen Columbowtrzel bekannte, von Coccuirs palmalus DC. abstammende Warzel enthiall das von W'iltstock darin entdeckte Columbin. (C. Biideker tellt dasselbe dar, indem er das alkoholische zur 'Trockue gebrachte Extract der Columbowurzeln in W'asser aufninınıl. die dicklich trübe Lösung mit ihrem gleichen Volum Aether mischt, die abgeschiedene ätherische Lisisung abhebil und so lange das Schütteln der wässerigen Lösung. mit Acther fortsetzi, als sich noch Columbin in demselben auflöst. Aus der abgedampften ätherischen Lösung krystallisirt dann das Columbin, entbält aber, wie die Multêr- 